rapidly follows. Exuberant granulations delay or prevent the process. Anything that would be mildly astringent and absorb moisture should prepare quickly a favourable bed of granulation tissue and thus hasten the protess of healing. It should be soluble in the ear secretion, otherwise it will clog the cavity. Boric acid fulfils these requirements. A satisfactory routine is as follows:

After operation the cavity is packed lightly and completely with dry lodoform half-inch ribbon gauzo. This is removed in five or six days. Thereafter plain half-inch ribbon gauze, shaken out of sifted boric acid powder, is packed evenly throughout the cavity. This is repeated daily. Eventually, when there is little secretion and the lining is flat, simple mopping followed by insufflating a thin film of powder is all that is required.

\section{Modified Radical Opērations}

Modified radical operations are performed to remove localized disease and preserve the good hearing present. Such disease is usually located in either or all of the following sites: the postero-superior margin of the tympanic annulus, the attic, the aditus, and the antrum.

I am convinced that there is only one operation worth considering. I refer to that type which differs from a radical operation only in so far that the remains of the tympanic membrane, together with the malleus and incus, are left in position. The bridge and outer attic wall must be removed. A very large proportion of these cases heal and dry with full preservation of hearing. It is a great mistake to remove the incus; as this seriously curtails the hearing. If the hearing is good the incus may be presumed to be quite healthy, or only slightly diseased. Slight disease consists merely in loss of small parts of its substance, and is in no way comparable to the gross osteitis which may exist, for instance, in the outer wall of the aditus or epitympanum. If, therefore, these parts be removed the incus will become buried in healthy granulations, and will heal over satisfactorily.

If it be argued that the pre-operative hearing was poor, or that the incus was found to be grossly diseased and its removal justifiable, then a full radical operation should be carried out, as poor hearing is very seldom made worse by this procedure. It is essential to remove the bridge and outer attic wall, which are frequently diseased and, furthermore, act as a barrier to drainage and epithelialization, which can only occur when the underlying areas are thrown open to healthy granulation tissue. No advantage is sacrificed by removing the bridge, but a wet ear is the common penalty of leaving it.

The soundness of these principles is fully borne out by observing and comparing the results of various types of modified radical operations. Extracting the incus, or leaving the bridge, dissatisfies the patient by reducing hearing or failing to stop the discharge. In that type of conservative operation which I have described as being highly successful, this is only the case if the various pitfalls in technique described in the radical operation are as carefully avoided in this one. The after-treatment should be the same, and care should be taken to avoid damaging the drum membrane.

\section{LOWER SEGMENT GAESAREAN SECTION*} BY

JAMES RIDDELL, M.C., M.D., F.R.C.S.ED., M.C.O.G. HONORARY GYNAECOLOGICAL SURGEON, PRINCE OF WALES'S HOSPITAL, PLYMOUTH

One of the chief advantages of this operation is that an extended "trial of labour" can be allowed with less danger to the patient. The operation can be performed before labour begins or after labour has been in progress. There is no need for the hurry that there may be in the performance of the "classical " operation in which the breech is delivered first. The contractile part of the uterus is not interfered with, bleeding is less, and consequently there is less danger of shock. The main defence of the patient against sepsis-namely, the blood-is conserved, and that is the outstanding reason why there is less danger" of sepsis. The suture line lies tucked away low down, and is less likely to cause omentum or bowel to become adherent to it. Adhesions between the uterus and the abdominal wall are not likely to occur.

\section{Necessity for X-Ray Examination}

Radiographs should be taken in cases which are considered likely to require Caesarean section. It would be regrettable to perform a Caesarean operation only to deliver an anencephalic foetus. The radiograph, by showing a collapsed vault of the skull, would prevent this mistake from being made. The presence of twins, unsuspected before radiography, might weigh the scale against operation. A breech presentation in an elderly primigravida might decide the accoucheur in favour of operation, not only to save damage to the pelvic floor of the patient, but to minimize the risk of losing the life of the child.

\section{Operative Technique}

After the patient has been anaesthetized the bladder should be catheterized and the vagina lightly packed with gauze wrung out of dettol solution or Bonney's paint.

* Read at a meeting of the South-Western Branch of the British Medical Association at Newquay, November 19th, 1935.
A short subumbilical incision is made and small towels are clipped to the edges of the wound, after which the peritoneal cavity is opened and packed off to avoid soiling. It is not necessary to use a self-retaining retractor, which requires a longer incision for its employment. Small retractors are preferable, particularly if the bladder is inclined to bulge into the wound. With a clean knife a transverse incision is made in the lower uterine segment just above the reflection of the peritoneum off the bladder, if possible without opening the amniotic cavity. The incision is enlarged with scissors, laterally and slightly upwards, sufficiently to allow the head to be delivered. I have used Bonney's compressor and Willett's forceps to lessen the haemorrhage in the making of the incision, but find that they are not required, as bleeding is generally only slight. Willett's forceps are sometimes useful in assisting the birth of the head.

The fingers of the right hand inserted gently inside the lower edge of the incision in the uterine wall coax the head from the uterus, whilst the left hand is employed outside the abdomen in manipulating the breech to faclitate the birth of the head. I intend to make trial of one blade of Wrigley's forceps instead of the fingers of the right hand, although the fingers can appreciate the resistance of the tissues better than an instrument and are less likely to cause damage. But one blade of Wrigley's forceps is easier to control than one blade of a long forceps, and its use would obviate the insertion of the hand into the uterus, to which practice there might be a serious objection. Suturing is made easy by marking the ends of the uterine incision with tissue forceps whilst the incision is still being stretched by the shoulders, then the shoulders and the rest of the body are delivered.

\section{Delivery of the Placenta}

Posterior pituitary extract $1 \mathrm{c.cm}$. is injected into the uterine wall and the placenta and membranes are delivered by manipulating the fundus of the uterus with the left hand outside the abdomen. The placenta separates quickly, and there is no need to wait for it as may be necessary in natural delivery. It is essential to remove the membranes completely, using in some cases a small dry towel with which to peel them off the lower segment. The hand does not need to be introduced into the uterus in order to secure the placenta.

After the lower edge of the uterine incision has been carefully defined threo mattress sutures of hardened catgut are inserted to control haemorrhage. It is important to define 
the lower edge of the incision because it is apt to retract beneath the bladder, and the unwary might sew the upper edge of the incision to the inside of the uterus instead of to the lower edge of the incision. A continuous interlccking suture is used to oversew the muscular layer which has already been approximated by the mattress sutures. The incision in the peritoneum covering the lower segment is closed with a continuous inverting suture. In a case potentially infected a drainage tube may be used for a few hours in the peritoneal cavity. The two sides of the incision in the parietal peritoneum are brought face to face, as advocated by. Blair-Bell in order to minimize the risk of bowel or omentum becoming adherent to the suture line.

The rest of the incision is closed in the usual way, finishing with a subcuticular suture or Michel's clips. In a fat subject it may be advisable to employ deep silkworm-gut sutures, but they may carry infection from the skin to the deeper layers of the wound, and they tend to spoil the appearance of the scar in the abdominal wall by leaving permanent marks, in spite of protection by fine rubber tubing.

\section{Convalescence}

Unless it is required to sterilize the patient the uterus is not brought outside the abdominal wall, for when the uterus is not eventrated there is less flatulent distension after operation. If the stomach is seen at operation to bo distended with gas a stomach tube may be passed before the patient leaves the operating theatre. I have been using the operation for some years, and am of opinion that it is not only a better operation to perform than the " classical " procedure, from the point of view of craftmanship, but it is followed by an easier convalescence.

BibliogRAPHY

Bonney, V.: Lancet, 1933, i, 796

Bailey, K. V.: Ibid., 1934, i, 672.

\section{PROGRESSIVE FAMILIAL HYPERTROPHIC NEURITIS (DEJERINE-SOTTAS)}

BY

ERIC L. COOPER, M.D.

MARION CARTY RESEARCH FELLOW IN THE WALTER AND ELIZA HALL INSTITUTE, MELBOURNE

In 1893 there was recorded by Déjerine and Sottas a distinct entity in the group of familial disorders to which the name " hypertrophic neuritis" was given." Cases were also described by Marie (1906), Boveri (1910), Yokomari (1915), and others, but in 1929 de Brugn and Stern $^{2}$ could find only twenty cases recorded in the literature. In the following paper at least four more cases are added, probably the first to be reported from Australia.

\section{Family History}

Briefly stated, the family consists of a woman aged $\mathbf{5 5}$ years and three of her sons, aged 28, 24, and 21 years, respectively. The notes of these cases are given in full. In the previous generation the mother of the female patient described here had wasting of the peripheral portions of all fcur limbs, and one other member of the family, at present in Queensland, is said to have the same disability, which is known as a "family weakness" : neither of these two has been examined by me.

The members of the family so far examined have marked wasting and loss of power in the lower limbs extending symmetrically as high as the junction of the lower and middle thirds of the thighs. The electrical reactions are those of " reaction of degeneration": fibrillary tremors are present in the muscles, and a secondary foot deformity of the "pes cavus" type occurs in each case. In the upper limbs there is wasting and weakness of the hands and forearms with the develop- ment of a claw-hand. The muscles of the arms, shoulders, trunk, neck, and upper two-thirds of the thighs show no change. There is loss of sensation to pin-prick and cotton-wool of glove and stocking type extending as high as the knees and elbows. The peripheral nerves are thicker than normal, especially the ulnar, and the trunks of the brachial plexus are also enlarged.

While the above signs are uniform throughout this family group some members have other abnormal neurological signs. Nystagmus, abnormal pupil reactions, and defects in speech are present in some, while others have loss of sensation to heat and cold and trophic changes in the hands.

\section{Case I}

The patient, a widow aged 55 years, has had weakness and wasting of her hands for over twenty years; even before this time she had noticed her hands to be "clumsy," particularly in cold weather. For about the same period she has had some difficulty in walking; the legs are weak, and she is liable to fall over if walking upon irregular ground. For at least thirty years her feet have been deformed. Occasional " numbness" in the left leg has been the only other symptom noted. She has always been in gocd general health, has brought up a family of five children, and still cooks and does all the work of a large house.

She is a rather thin, short woman of nervous type. The hands are small and the grip is weak, the muscles of the thenar and hypothenar eminences being almost completely atrophied and the forearms wasted to a marked degree. The muscular development of the arms and shoulders is normal. The supinator jerks are absent, but the biceps and triceps jerks are overactive. There is no tremor or fibrillation. In contrast to the normal thighs the legs are thin, and there is a very gross bilateral " pes cavus." The knee-jerks are active, and the hamstring jerks overactive, but the anklejerks and plantar reflexes are absent. The muscles of the calves show fibrillary tremors.

There is loss of sensation to pin-prick, cotton-wool, and to heat and cold of the glove type to the elbow and of the stocking type to the knee. Vibration sense and sense of position are normal and there is no ataxia. Cranial nerves are normal, the mental condition is good, and the sphincters are not affected. The peripheral nerves all seem larger tilan normal and are insensitive to pressure.

\section{Case II}

The first son, aged 28 years, a cook by occupation, has a long-standing deformity of his feet. For five years there has been progressive wasting and weakness of the hands and forearms, and recently he was compelled to give up his work as a cook owing to inability to lift heavy utensils. $\mathrm{He}$ is unsteady on his feet, and the muscles of the calves of his legs have gradually wasted. He frequently burns his hands at his work and only realizes this when blisters develop. His speech has become slurred, especially during the past few months.

The patient is a healthy-looking adult, with extremely welldeveloped shoulders, trunk muscles, and thighs (see Fig.). The small muscles of the hands are wasted, with the development of a bilateral claw-hand. All movements of the hands and wrists are weak, while at the elbow and shoulder power appears normal. Fibrillary tremors are present in the thenar eminence on the left side and in both forearms. The biceps and triceps jerks are active, the supinator jerks being greatly reduced on both sides. In the lower limbs there is bilateral " pes cavus," with wasting of the muscles of the calves and distal thirds of the thighs, the muscles being replaced by a firm 